\title{
Eating well at your first job
}

\author{
Anthony W. Kim, MD, and Vaughn A. Starnes, MD
}

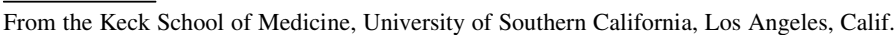 \\ Disclosures: Authors have nothing to disclose with regard to commercial support. \\ Received for publication June 9, 2018; revisions received June 9, 2018; accepted for publication June 11, 2018 \\ Address for reprints: Anthony W. Kim, MD, Division of Thoracic Surgery, Keck School of Medicine, University \\ of Southern California, 1510 San Pablo St, Suite 514, Los Angeles, CA 90033 (E-mail: anthony.kim@med.usc. \\ edu). \\ J Thorac Cardiovasc Surg 2018;156:1585-6 \\ $0022-5223 / \$ 36.00$ \\ Copyright (C) 2018 Published by Elsevier Inc. on behalf of The American Association for Thoracic Surgery \\ https://doi.org/10.1016/j.jtcvs.2018.06.041
}

In business, the saying that "culture eats strategy for breakfast" is commonly used to describe challenging environments. Among the many variables a young trainee must evaluate regarding a job, assessing the culture may be one of the tougher tasks. Any practice that is recruiting you will be placing its best foot forward during the interview process. Therefore, conversations and observations during the interview visits may not lend themselves to seeing some of the realities associated with a position. In all fairness, most employers are forthright about the areas in which there are opportunities for improvement. In truth, your recruitment represents an effort to fill a need whether it is to tackle growing volume, to bolster their position in the marketplace because of a special skillset that you can provide, or to address other issues. So from the start, you will be valued.

Figuratively and literally, many understand that as a new graduate you are starving to get out into the real world and perform all that you have been working toward in your training. Every employer recognizes that it has taken you approximately a decade to get to the point where you can literally taste the proverbial "it." Although money to some degree is the value that a potential employer places on you, it should not be the overly dominant factor that is considered. Despite the information that is provided by the Medical Group Management Association or the Association of American Medical Colleges, their reported salary figures represent means or medians that include those surgeons who, for some time and for a variety of reasons, have remained at their rank or in the same position at which you are entering. Most practices will offer a compensation package that is comparable to the practices competing for business in the same region and possibly even competing for you. As you weigh the offers, you must view the value proposition from the perspective of the employer. Although your references will speak in glowing terms about you, most practices are risk averse in the current economic climate and you are an unproven product. Therefore, presuming that the initial package offered is relatively competitive, other considerations such as how the culture of the practice will

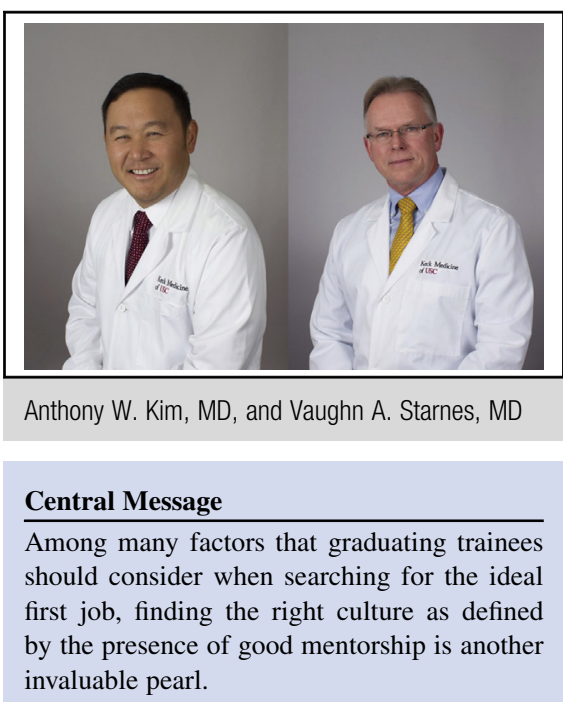

See Article page 1575.

support your growth, professionally and in other facets, should move to the forefront.

Central to good culture is good leadership and good mentorship. They are often one in the same. Leaders in good cultures will recognize the necessity of increasing your support in a manner commensurate with your clinical growth when it happens. With each success, you also will need good mentorship to navigate many issues that most assuredly will arise throughout your ascent. This mentorship will potentiate your growth to an extent that will eclipse what you think you may learn from having gained increased clinical experience alone. It is important to recognize that good mentorship comes in many different forms. It can range from the very obvious, such as providing assistance without hesitation in the operating room when you ask, to the more subtle, such as when the mentor asks you for assistance in the operating room, underscoring your significance as an equal. Characterizing good mentorship would be an endless topic unto itself, but it can be distilled into the simple fact that in whatever form it manifests, it reflects a healthy culture that sets the table for future triumphs.

Conducting your own due diligence is key to identifying the culture that is right for you. Just as you know that a potential employer is using the interview process to inquire about you, you should reciprocate this effort to become aware of both the facts and the nuances of the practice. Use your strong and weak ties from the past to learn more 
from individuals who have observed the practice from the outside or inside, especially by those individuals who hold a longer chronologic perspective.

In this issue of the Journal, Macke and colleagues ${ }^{1}$ have provided an incredibly useful soup-to-nuts roadmap for finding the best first job. Among many outstanding points, they also make the astute statement that "...no cascade of ancillary benefits will adequately compensate for this..." in reference to working in a culture that is not ideal for you. The corollary to this sentiment is that the value of good mentorship is immeasurable. You have certainly put in the time and effort to enjoy the fruits of your labor. Good culture lets you eat these fruits and more!

\section{Reference}

1. Macke RA, Ghanta R, Starnes S, Harken AH. So, you are looking for a job: pearls for a successful first cardiothoracic job search. J Thorac Cardiovasc Surg. 2018; $156: 1575-84$. 